\title{
National Library of Sweden (LIBRIS) Holding ISBN 8366675580
}

Stockholm, S-102 41 Sweden.

(C) LIBRIS - National Library Systems

http:/ libris.kb.se/ bib/ gv0mzf17ddfpmqsj

September 17, 2021

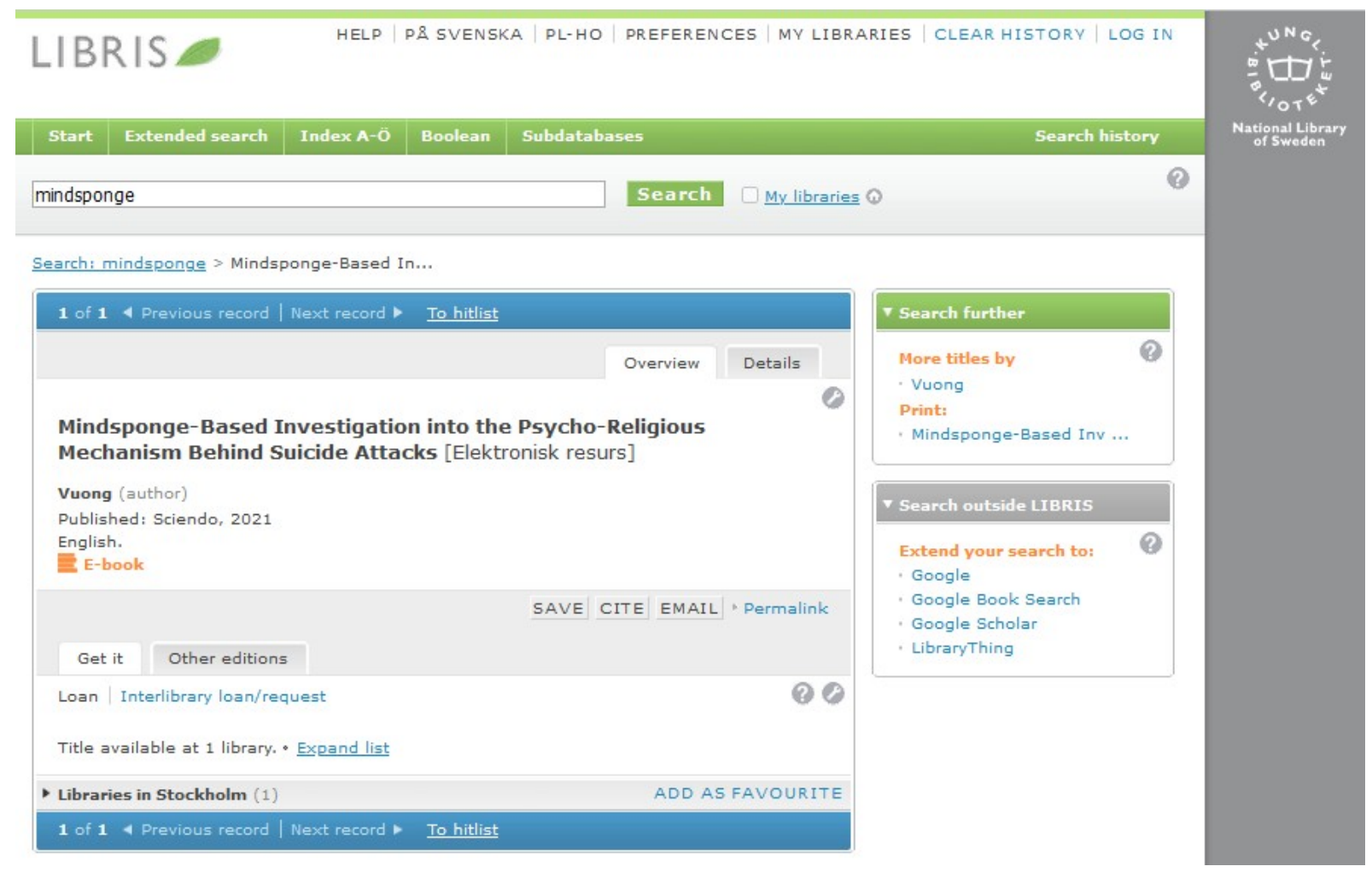


Sökning: onr:gvomzf17ddfpmqsj > Mindsponge-Based In...

- Vuong (författare)

\section{Mindsponge-Based Investigation into the Psycho-Religious Mechanism Behind Suicide Attacks [Elektronisk resurs]}

- E-bokEngelska 2021

\section{Förlag, utgivningsår, omfång ...}

- Publicerad: Sciendo, Publicerad: 2021

\section{Nummerbeteckningar}

- LIBRIS-ID: gvomzf17ddfpmqsj

- Ogiltigt nummer / annan version: 8366675580 (print)

\section{Kompletterande språkuppgifter}

- Språk: engelska

\section{Sammanhörande titlar}

- Annan version: Print: Mindsponge-Based Investigation into the Psycho-Religious Mechanism Behind Suicide Attacks 8366675580

Titeln finns på 1 bibliotek.

\section{Bibliotek i Stockholmsregionen (1)}

Kungliga biblioteket hanterar dina personuppgifter i enlighet med EU:s dataskyddsförordning (2018), GDPR. Läs mer om hur det funkar här. Så här hanterar KB dina uppgifter vid användning av denna tjänst.

Copyright (C) LIBRIS - Nationella bibliotekssystem 
